\title{
Technical note: Evaluation of a system for monitoring rumination in heifers and calves
}

\author{
O. Burfeind, ${ }^{\star} \dagger$ K. Schirmann, ${ }^{\star} \dagger$ M. A. G. von Keyserlingk, $\dagger$ D. M. Veira,‡ D. M. Weary, $\dagger$ and W. Heuwieser ${ }^{\star} \dagger^{1}$ \\ ${ }^{*}$ Clinic for Animal Reproduction, Faculty of Veterinary Medicine, Freie Universität Berlin, 14163 Germany \\ †Animal Welfare Program, Faculty of Land and Food Systems, The University of British Columbia, Vancouver V6T 1Z4, Canada \\ $\ddagger$ Agriculture and Agri-Food Canada, Pacific Agriculture Research Station, Agassiz, BC
}

\section{ABSTRACT}

The Hi-Tag electronic rumination-monitoring system (SCR Engineers Ltd., Netanya, Israel), based on capturing audio recordings, provides a reasonable measure of rumination time in dairy cows, but has not been validated for milk-fed or weaned heifers. The objective of this study was to validate the Hi-Tag ruminationmonitoring system in heifers and calves and to assess whether suckling from a teat interfered with recording from this system. Assessments of 2 independent observers were highly correlated $(\mathrm{r}=0.99, \mathrm{n}=20)$, indicating that direct visual observations provide a useful standard. Measures from the Hi-Tag system were validated by comparing values with those from a single human observer, using observations from three 2 -h intervals from 35 Holstein calves and heifers aged 4, 6, and $9 \mathrm{wk}$ and 3,6, and 9 mo, respectively. In 9-mo-old heifers, rumination times obtained from the electronic system were highly correlated with visual observations ( $\mathrm{r}=$ $\left.0.88, \mathrm{R}^{2}=0.77, \mathrm{n}=15\right)$, and the mean difference was minor ( $-4 \pm 8 \mathrm{~min} / 2$-h interval). The accuracy of data from the automated system decreased when used on heifers less than 9 mo old. Suckling did not interfere with the electronic system $(\mathrm{r}=-0.1, \mathrm{n}=18)$. These results indicate that the Hi-Tag system is an accurate tool for monitoring rumination behavior in Holstein Friesian heifers from the age of 9 mo.

Key words: heifer calf, rumen development, rumination behavior, validation

Rumination is the process of regurgitating ingesta from the reticulorumen into the mouth, where the bolus is masticated and mixed with saliva for 30 to $60 \mathrm{~s}$ and reswallowed (Beauchemin, 1991). Rumination is characterized by a repetitive series of short boli separated by short pauses and it reduces the particle size of feedstuffs, which enables microbial digestion and

Received March 8, 2010.

Accepted September 12, 2010.

${ }^{1}$ Corresponding author: wolfgang.heuwieser@ubc.ca increases saliva secretion as the most important buffer for ruminal pH (Beauchemin, 1991).

Rumen development is associated with dramatic physiological changes (Baldwin et al., 2004) as calves change from monogastric digestion to digestion with microbial fermentation in the forestomach (Huber, 1969) and the onset of rumination. Together, these processes cause a shift in the patterns of the nutrients delivered to the liver (Baldwin et al., 2004). Calves can start ruminating at approximately 1 to 2 wk of age (Swanson and Harris, 1958; Gilliland et al., 1962; Babu et al., 2004). Rumination times increase until the calf is approximately 4 to $6 \mathrm{wk}$ old, leveling out at approximately 5 h/d (Swanson and Harris, 1958; Margerison et al., 2003). For heifers, Rotger et al. (2006) and Robles et al. (2007) reported similar times spent ruminating $(132.3 \pm 1.61$ and $385 \pm 6.2 \mathrm{~kg}$, respectively). Adult dairy cows ruminated 7 to $8 \mathrm{~h} / \mathrm{d}$ in a recently published study (Adin et al., 2009). Diet composition plays a major factor in determining rumination times, with increased forage intakes resulting in increased rumination time (Yang et al., 2001; Maekawa et al., 2002).

There is still a lack of knowledge about how to measure rumen development reliably (Roth et al., 2009). However, it has been indicated that rumination accompanies or precedes the development of normal rumen function and fermentation (Swanson and Harris, 1958). Furthermore, in a recently published study by Borderas et al. (2008), calves injected with lipopolysaccharides decreased the time spent ruminating from $24.6 \pm 6.6$ to $6.4 \pm 3.7 \mathrm{~min}$ in the 4 -h time period when they also had a fever. That said, monitoring rumination in calves might be a useful tool to study rumen development and to detect calves at risk of illness.

Quantifying rumination behavior using direct visual observations (Margerison et al., 2003; Babu et al., 2004) or video recordings (Rotger et al., 2006; Robles et al., 2007; Borderas et al., 2008) is time consuming. The Hi-Tag rumination-monitoring system (SCR Engineers Ltd., Netanya, Israel) provides a reasonable measure of rumination time in dairy cows (Schirmann et al., 2009). However, this technology has not been validated 
for measuring rumination in young cattle. The overall objective of this study was to evaluate the Hi-Tag system for monitoring rumination in heifers and calves. Specifically, the objectives were (1) to determine interobserver repeatability of rumination data collected via direct human observation in heifers and calves, (2) to determine the accuracy of the Hi-Tag rumination-monitoring system compared to direct visual observation in heifers and calves considering different ages, and (3) to study whether the sound of milk suckling in bottlefed, preweaned calves interferes with the ruminationmonitoring system.

Three experiments were conducted at The University of British Columbia's Dairy Education and Research Centre (Agassiz, BC, Canada) between May and August 2009. Animals were managed according to the guidelines set by the Canadian Council of Animal Care (1993). A total of 44 Holstein Friesian heifers and calves were used. In this manuscript, animals were considered to be calves from birth until weaning (groups 1,2 , and 3 ), and all weaned animals were defined as heifers (groups 4, 5, and 6). Calves were bottle fed (Little Giant nursing bottle, Miller Manufacturing Co., Glencoe, MN) $4 \mathrm{~L}$ of pasteurized milk twice a day (approximately 0800 and $1600 \mathrm{~h}$ ). The milk amount was decreased to $3 \mathrm{~L}$ twice a day on d $50( \pm 5)$ and $2 \mathrm{~L}$ twice a day on d $60( \pm 5)$. Calves were weaned on d $70( \pm 5)$. All calves were provided hay and a barley-based calf starter ad libitum from the second week of life. Heifers were fed a TMR once a day (at approximately $0800 \mathrm{~h}$ ) comprising $52.6 \%$ alfalfa hay, $23.0 \%$ concentrate and mineral mix, $15.3 \%$ grass silage, and $9.1 \%$ corn silage on a DM basis (61\% DM). Feed was pushed up at 1400, 1800 , and $2200 \mathrm{~h}$. In experiments 1 and 2, animals were moved to an observation pen, weighed, and fitted with rumination loggers $15 \mathrm{~h}( \pm 1)$ before the observations were conducted. The observations were performed with a time delay of at least $2 \mathrm{~h}$ to feeding or push-up times to monitor a quiet period in the barn, ensuring high rumination activity. During the observational period, all animals were housed individually (groups 1, 2, 3: $2.0 \mathrm{~m} \times 1.2 \mathrm{~m}$; groups 4, 5, 6: $12.8 \mathrm{~m} \times 4.7 \mathrm{~m})$, but were able to maintain visual and acoustic contact with other animals. Sawdust bedding was used in all pens and replenished as needed. After the three 2-h observational periods on each animal, the rumination loggers were removed and the data downloaded by a handheld readout unit.

The rumination logger contains a microphone that captures the distinctive sounds produced when the animal regurgitates the bolus and ruminates. Data are processed and digitally stored within the recording unit (see Schirmann et al., 2009 for specific details). Data from these loggers is processed in 2-h bins, so all observation periods reported below are $2 \mathrm{~h}$ long.

A counterweight $($ size $=70 \mathrm{~mm} \times 70 \mathrm{~mm} \times 30 \mathrm{~mm}$; weight $=540 \mathrm{~g}$ ) was attached to the collar to ensure the logger retained its position 5 to $10 \mathrm{~cm}$ behind the left ear in the upper third of the neck in heifers (groups 4,5 , and 6 ). In younger calves (groups 1,2 , and 3 ), we omitted the counterweights to prevent any potential discomfort for the calves due to their small stature. That said, the logger was positioned accordingly and the observer carefully ensured the correct position during the observation period.

In experiment 1, 2 observers independently recorded rumination behavior from 20 animals (11 heifers, 208 $\pm 78 \mathrm{~d}, 244 \pm 100 \mathrm{~kg} ; 9$ calves, $46 \pm 14 \mathrm{~d}, 86 \pm 15 \mathrm{~kg}$ ) via direct human observation for a period of $2 \mathrm{~h}$ each to determine interobserver reliability. Observers recorded the start time when a bolus reached the mouth and the animal began to chew rhythmically, as well as the ending time when the bolus was swallowed. This was used to calculate the elapsed time between successive regurgitation events, the length of a rumination bout, and the elapsed time between an individual bolus being swallowed and the regurgitation of subsequent boluses. Both observers were equipped with laptop computers and recorded the different events using the stopwatch function in Excel (version 2003, Microsoft, Redmond, WA). During the observation periods, the 2 observers did not communicate with each other and were unable to view the other's computer display. Observers were positioned outside the pen but with an unobstructed view of the individual animal housed in the pen.

In experiment 2, 6 groups were used to test the accuracy of the Hi-Tag rumination-monitoring system compared with direct visual observation. The groups consisted of 5 animals each (except for group 4, which had 10 animals) of similar age and BW (Table 1). For each animal, rumination time was determined by visual observation and with a rumination logger for three 2-h observation periods on a single day. All observations were performed by the same observer, who was one of the observers in experiment 1.

In experiment 3, we tested the effect of calves sucking milk through a nipple on recordings from the Hi-Tag system. Each of 9 calves $(20 \pm 22 \mathrm{~d})$ was fitted with a rumination logger just before milk feeding in the morning (approximately $0800 \mathrm{~h}$ ) and again in the afternoon (approximately $1600 \mathrm{~h}$ ), and allowed to drink milk from the nipple. Loggers were removed immediately after the calves had finished their milk meal $(6 \pm 2 \mathrm{~min})$ and were placed in a quiet room until the 2 -h recording period was complete. Because the calves were equipped with the loggers only during their milk meal $(6 \pm 2$ 
Table 1. Correlation, estimates of rumination, and differences per 2-h interval of paired measurements of rumination time (minutes; mean \pm $\mathrm{SD}$ ) recorded by the Hi-Tag (SCR Engineers Ltd., Netanya, Israel) system and direct visual observation

\begin{tabular}{|c|c|c|c|c|c|c|c|c|c|c|c|}
\hline Group $^{1}$ & $\begin{array}{l}\text { Age } \\
\text { (d) }\end{array}$ & $\begin{array}{l}\text { BW } \\
(\mathrm{kg})\end{array}$ & $\mathrm{r}$ & $P$-value & $\mathrm{R}^{2}$ & $\begin{array}{l}\text { Rumination } \\
\text { time, visual } \\
\text { observation }\end{array}$ & $\begin{array}{l}\text { Rumination } \\
\text { time, Hi-Tag } \\
\text { system }\end{array}$ & $\underset{(\min )}{\operatorname{Mean} \pm \mathrm{SD}}$ & Paired $t$ & $P$-value & $\begin{array}{c}\text { Variation } \\
(\%)\end{array}$ \\
\hline 1 & $25 \pm 2$ & $64 \pm 3$ & 0.65 & 0.009 & 0.42 & $22 \pm 14$ & $14 \pm 12$ & $-8 \pm 10$ & 2.99 & 0.01 & 14.7 \\
\hline 2 & $42 \pm 2$ & $80 \pm 15$ & 0.70 & 0.004 & 0.49 & $26 \pm 16$ & $26 \pm 14$ & $0 \pm 12$ & 0.30 & 0.77 & 14.4 \\
\hline 3 & $62 \pm 1$ & $90 \pm 11$ & 0.89 & 0.001 & 0.79 & $28 \pm 16$ & $30 \pm 22$ & $2 \pm 10$ & 0.53 & 0.60 & 11.8 \\
\hline 6 & $282 \pm 7$ & $342 \pm 14$ & 0.88 & $<0.001$ & 0.77 & $28 \pm 16$ & $24 \pm 14$ & $-4 \pm 8$ & 2.18 & 0.05 & 7.8 \\
\hline
\end{tabular}

${ }^{1}$ Groups comprised 5 animals, each measured 3 times to generate 15 paired measures per group (except group 4 , which contained 10 animals and generated 30 paired measures).

${ }^{2}$ Rumination loggers - visual.

min), the loggers could not record any rumination activity during the 2 -h test period. To generate a negative control, collars were left in the same quiet room for another 2-h period.

Data were recorded in Excel and statistically analyzed with Medcalc (v. 10.1.3.0, MedCalc software, Mariakerke, Belgium). To determine interobserver reliability, Pearson coefficients of correlation were calculated. The relationship between rumination time collected via direct observations (independent variable) and via the rumination loggers (dependent variable) was also evaluated by Pearson correlation and linear regression. The difference between rumination data recorded via direct observation and the rumination logger and the difference between rumination data recorded by 2 observers independently was tested using a paired $t$-test. The Hi-Tag system records rumination with a resolution of $2 \mathrm{~min}$, which results in 60 possible agreements or disagreements per 2-h interval between data recorded by direct observation and through the Hi-Tag system. To quantify discrepancies, the percentage of disagreements was calculated by dividing the absolute value of the difference between the time of rumination recorded by direct observation and the Hi-Tag system by 60 . All statistical parameters were analyzed for each group individually. The relationship between time sucking on the milk bottle nipple and the time recorded by the rumination loggers in experiment 3 was evaluated by Pearson correlation.

The rumination times recorded by the 2 independent observers were highly correlated $(\mathrm{r}=0.99, P<0.001$, $\mathrm{n}=20)$ and average differences (mean $\pm \mathrm{SD}$ ) were small $(0 \pm 2 \mathrm{~min}, P=0.91)$. Average interobserver variation was $4.0 \%$; the maximum variation between measures of a single observation was $16.4 \%$. These results are comparable to those observed for adult dairy cows (Schirmann et al., 2009) and demonstrate that rumination times also can be assessed reliably through direct observation in calves and growing heifers.

The relationship, differences, and variation among estimates of rumination time by direct observation and the estimates of rumination time measured by the Hi-Tag rumination-monitoring system varied between the different groups (Table 1). Coefficients of correlation and determination were highest for group 3 and 6 , respectively. For groups 1, 2, and 5, coefficients of correlation and coefficients of determination were lower but comparable and were lowest in group 4 (Table 1).

The differences between estimates provided by direct observation and the Hi-Tag system were lowest in groups 2,3 , and 6 . They were comparable in groups 1 and 5 and highest in group 4 (Table 1). As described, $P$-values differed among groups $(<0.001$ to 0.77 ; Table 1 ), with values less than 0.05 in groups 1,4 , and 5 illustrating a significant difference between the 2 estimates in these groups.

Variation in the difference between estimates provided by direct observation and the Hi-Tag system was low in groups 6 and 3, but higher in groups 1, 2, 4 , and 5 , respectively (Table 1 ). To illustrate absolute differences of estimates of rumination time by direct observation and the Hi-Tag system, we plotted the difference between the 2 methods for each 2-h observation period and every animal per group (Figure 1).

When provided with milk, calves drank for $6 \pm 2$ min. The coefficient of correlation between drinking time determined by direct observation and "rumination"" recorded by the Hi-Tag system was low ( $\mathrm{r}=-0.1, P=$ $0.70, \mathrm{n}=18)$. No rumination time was recorded in 16 of the 18 2-h periods recorded by the Hi-Tag system. In both of the other 2-h observational periods, only a single 2-min observation was recorded. No rumination time was recorded during any of the 18 negative control intervals. These results indicate that the sound 

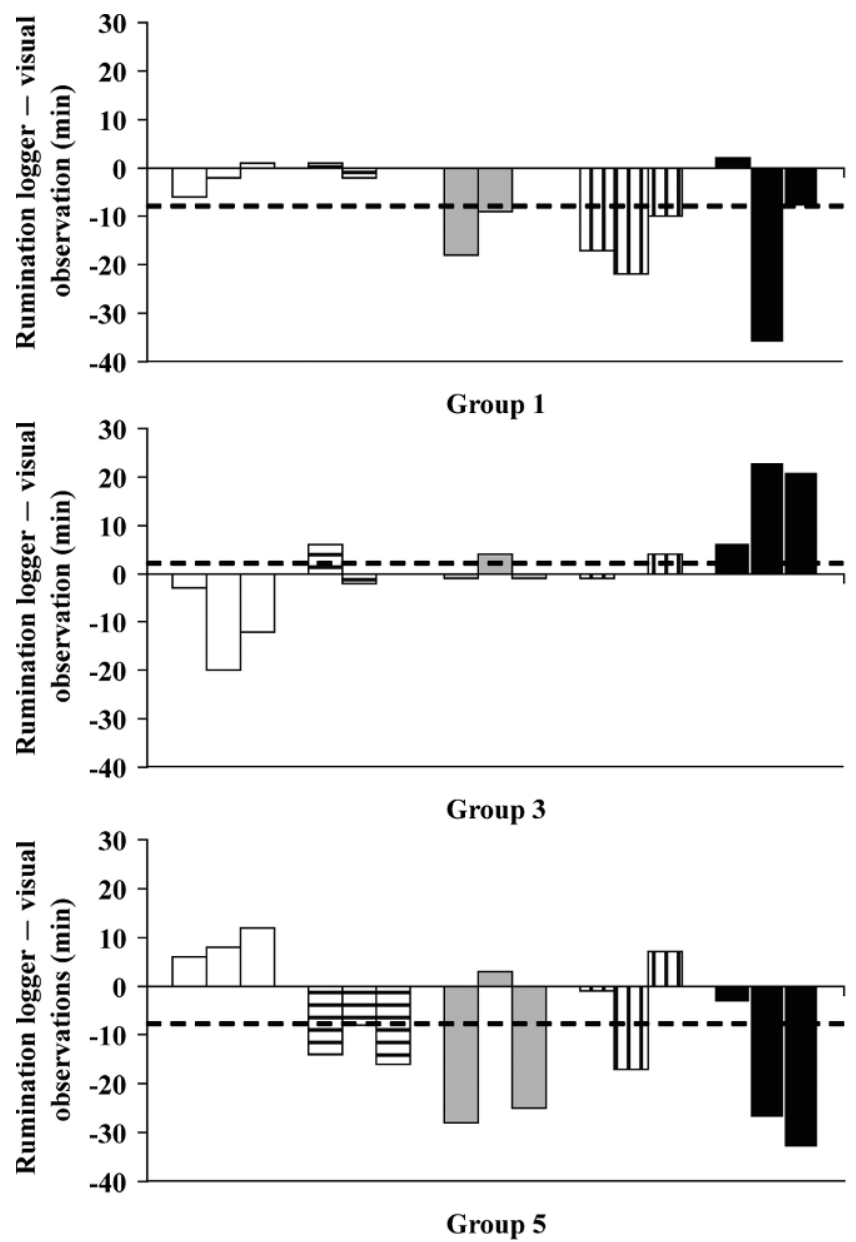
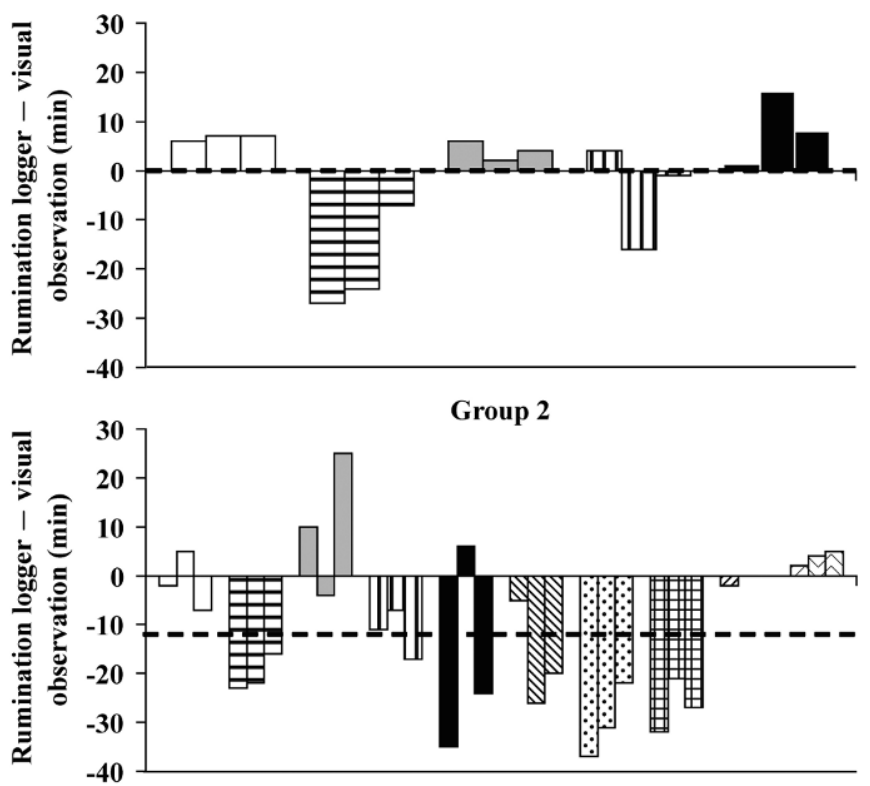

Group 4

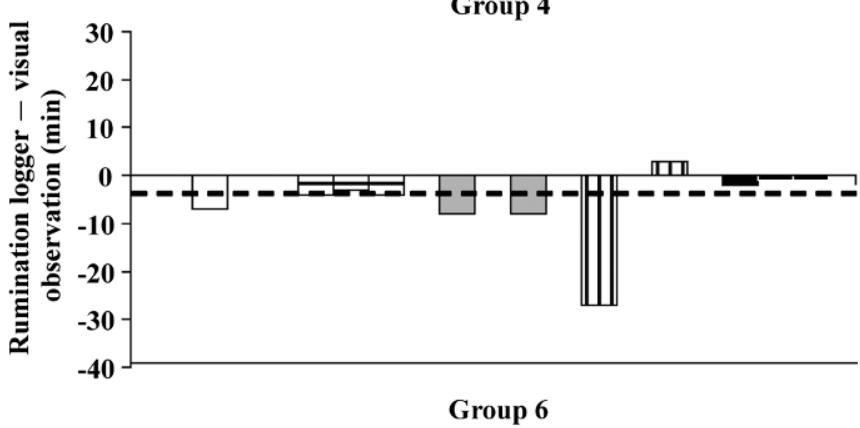

Figure 1. Difference among estimates of rumination time by the Hi-Tag system (SCR Engineers Ltd., Netanya, Israel) and direct visual observation ( $\min$ ) per 2-h interval (rumination loggers - visual; - - - = mean difference). Values within each group are sorted by animal; animals within group are differentiated by color and pattern. Negative values indicate an underestimation by the Hi-Tag system, whereas positive values indicate an overestimation.

of drinking milk from a nipple does not interfere with recordings by the Hi-Tag system.

These results demonstrate that the Hi-Tag rumination-monitoring system does provide a reasonable measure of rumination in heifers older than $9 \mathrm{mo}$; recordings on animals of this age were highly correlated $(\mathrm{r}=0.88)$ with live observations with little numerical difference between the values (variation $=7.8 \%$ ). In comparison, a recent study on cows (Schirmann et al., 2009) reported correlation coefficients of 0.92 to 0.96 and variation of approximately $6 \%$.

The reasons for the lower accuracy of the Hi-Tag system in younger animals remain unclear. Although the Hi-Tag system differentiates among rumination and feeding activity in adult dairy cattle (Schirmann et al., 2009) and does not record the sounds of drinking milk in calves, technical limitations cannot be completely ruled out. Differentiating among sounds associated with rations of different composition (e.g., hay, concentrate) might be confounding data measured with the Hi-Tag system in dairy calves. Furthermore, we speculate that amplitude and frequency of the sounds generated by the rumination process might be different in calves compared with cows and thus reduce the accuracy of the rumination-monitoring system that was developed for use in adult cows. These factors may help to explain the variability in accuracy of the Hi-Tag systems for calves of different ages. We cannot offer a satisfactory explanation as to why the accuracy of the electronic system increased in group 3 calves, but we encourage future work in this area. Better positioning of the collars might have improved estimates from the system for older animals. Based on the highly correlated relationship between rumination data determined by 2 
independent observers individually as a useful standard in experiment 1, we suggest that error due to the direct visual observation is minimal.

In summary, the Hi-Tag rumination-monitoring system can provide a reasonable estimate of rumination time in Holstein heifers older than 9 mo. In animals younger than 9 mo, variation in the data is high. However, an automatic detection of rumination time in heifers and calves might be a useful tool for detection of illness or for studying rumen development in calves. Considering that sucking does not confound rumination time measures, further research is encouraged to optimize the sound-based detection system for rumination in calves.

\section{ACKNOWLEDGMENTS}

We thank the staff of The University of British Columbia Dairy Education and Research Centre and the University's Animal Welfare Program (Vancouver, BC, Canada). In particular, we thank M. A. Khan for his help with the visual observations. Onno Burfeind was funded by a scholarship from Tiergyn Berlin e.V. (Berlin, Germany). This project was funded by the Natural Sciences and Engineering Research Council of Canada, the Dairy Farmers of Canada, the Freie Universität Berlin, and many donors listed at http://www. landfood.ubc.ca/animalwelfare.

\section{REFERENCES}

Adin, G., R. Solomon, M. Nikbachat, A. Zenou, E. Yosef, A. Brosh, A. Shabtay, S. J. Mabjeesh, I. Halachmi, and J. Miron. 2009. Effect of feeding cows in early lactation with diets differing in roughageneutral detergent fiber content on intake behavior, rumination, and milk production. J. Dairy Sci. 92:3364-3373.

Babu, L. K., H. N. Pandey, and A. Sahoo. 2004. Effect of individual versus group rearing on ethological and physiological responses of crossbred calves. Appl. Anim. Behav. Sci. 87:177-191.
Baldwin, R. L. VI, K. R. McLeod, J. L. Klotz, and R. N. Heitmann. 2004. Rumen development, intestinal growth and hepatic metabolism in the pre- and postweaning ruminant. J. Dairy Sci. 87(Suppl.):E55-E65.

Beauchemin, K. A. 1991. Ingestion and mastification of feed by dairy cattle. Vet. Clin. North Am. Food Anim. Pract. 7:439-463.

Borderas, T. F., A. M. B. de Passille, and J. Rushen. 2008. Behavior of dairy calves following a low dose of bacterial endotoxin. J. Anim. Sci. 86:2920-2927.

Canadian Council on Animal Care. 1993. Guide to the Care and Use of Experimental Animals. Vol. 1. E. D. Olfert, B. M Cross, and A. A. McWilliam, ed. CCAC, Ottawa, ON, Canada.

Gilliland, R. L., L. J. Bush, and J. D. Friend. 1962. Relation of ration composition to rumen development in early-weaned dairy calves with observations on ruminal parakeratosis. J. Dairy Sci. 45:1211-1217.

Huber, J. T. 1969. Development of the digestive and metabolic apparatus of the calf. J. Dairy Sci. 52:1303-1315.

Maekawa, M., K. A. Beauchemin, and D. A. Christensen. 2002. Effect of concentrate level and feeding management on chewing activities, saliva production, and ruminal $\mathrm{pH}$ of lactating dairy cows. J. Dairy Sci. 85:1165-1175.

Margerison, J. K., T. R. Preston, N. Berry, and C. J. C. Phillips. 2003. Cross-sucking and other oral behaviours in calves, and their relation to cow suckling and food provision. Appl. Anim. Behav. Sci. 80:277-286.

Robles, V., L. A. Gonzalez, A. Ferret, X. Manteca, and S. Calsamiglia. 2007. Effects of feeding frequency on intake, ruminal fermentation and feeding behavior in heifers fed high-concentrate diets. J. Anim. Sci. 85:2538-2547.

Rotger, A., A. Ferret, X. Manteca, J. L. R. de la Torre, and S. Calsamiglia. 2006. Effects of dietary nonstructural carbohydrates and protein sources on feeding behavior of tethered heifers fed highconcentrate diets. J. Anim. Sci. 84:1197-1204.

Roth, B. A., N. M. Keil, L. Gygax, and E. Hillmann. 2009. Influence of weaning method on health status and rumen development in dairy calves. J. Dairy Sci. 92:645-656.

Schirmann, K., M. A. G. von Keyserlingk, D. M. Weary, D. M. Veira, and W. Heuwieser. 2009. Technical note: Validation of a system for monitoring rumination in dairy cows. J. Dairy Sci. 92:60526055 .

Swanson, E. W., and J. D. Harris Jr.. 1958. Development of rumination in the young calf. J. Dairy Sci. 41:1768-1776.

Yang, W. Z., K. A. Beauchemin, and L. M. Rode. 2001. Barley processing, forage: Concentrate, and forage length effects on chewing and digesta passage in lactating cows. J. Dairy Sci. 84:2709-2720. 